\title{
Effectiveness of Cognitive-Behavioral Therapy and Acceptance and Commitment Therapy on Psychosocial Needs of Veterans
}

\section{ART ICLE INF O}

\section{Article Type}

Original Research

\section{Authors}

Asgharnejad Farid AA. ${ }^{* 1} P h D$,

Mirmohammadali M. ${ }^{2} P h D$,

Ahadi $\mathrm{H}^{3} \mathrm{PhD}$

Nasiri A. ${ }^{4} P h D$

\section{A B S T R A C T}

Aims Mental disorders are a common problem in combatants, veterans, and their families. This study aimed to evaluate the effectiveness of cognitive-behavioral therapy and treatment based on acceptance and commitment to veterans' psychosocial needs.

Materials \& Methods This quasi-experimental study was conducted with a pretest-posttest design with a control group in all psychiatric veterans in Tehran in 2018. Thirty psychiatric veterans were purposefully selected and were randomly assigned to two experimental groups (10 people each) and a control group (10 people). Data were collected using the Basic Psychological Needs, Post Traumatic Stress, Acceptance, and Operation Questionnaires. Cognitive-behavioral therapy sessions and acceptance and commitment-based therapy were held in 10 sessions, twice a week, for 90 minutes in each session for the experimental groups. Data were analyzed using SPSS 24 software and multivariate analysis of covariance and independent t-test.

Findings Cognitive-behavioral therapy could significantly affect veterans' basic psychological needs and their components and increase the capacity of basic needs in veterans undergoing cognitive-behavioral therapy compared to the control group. Also, acceptance and commitment therapy could have a significant effect on the basic psychological needs and the component of autonomy and competence of veterans $(p<0.05)$, but this effect was not significant on the component of communication with others $(p>0.05)$.

Conclusion Cognitive-behavioral therapy and therapy based on acceptance and commitment affect the veterans' basic psychological needs.

Keywords Psychosocial Needs; Veterans; Cognitive Behavioral Therapy; Acceptance and Commitment Therapy
${ }^{1}$ Department of Psychology, Psychology Faculty, Iran University of Medical Sciences, Tehran, Iran

${ }^{2}$ Department of Psychology, Psychology Faculty, Edalat University, Tehran, Iran

32Department of Psychology, Psychology Faculty, Allameh Tabatabaei University, Tehran, Iran

${ }^{4}$ Sadr Psychiatric Hospital, Tehran, Iran

\section{*Correspondence}

Address: School of Behavioral Sciences and Mental Health, Shahid Mansouri Street, Niyayesh Street, Satarkhan Avenue,Tehran, Iran. Postal code: 1445613111. Phone: +98 (21) 66551655 Fax: +98 (21) 66551655 asgharnrjad.ali@gmail.com

\section{Article History}

Received: September 12, 2020

Accepted: January 16, 2021

ePublished: March 14, 2021

\section{I T A T I O N L I N K S}

[1] Study of telemental health services for veterans from viewpoints ... [2] Psychologicalsocial consequences chemical bombardment of the Sardasht victims ... [3] Prioritizing the needs of Guilan province's less than 25\%veterans from the ... [4] The effectiveness of acceptance and commitment therapy on reduction, generalized anxiety ... [5] Effectiveness of Acceptance and Commitment Therapy in treating depression ... [6] The effectiveness of cognitive-behavioral therapy on increasing the ... [7] Synopsis of psychiatry behavioral sciences/... [8] Effectiveness of cognitive behavioral therapy in war post traumatic stress ... [9] Cognitive-behavioral Therapy of Patients with PTSD: ... [10] Psychopathology based ... [11] The relationship between basic need satisfaction and general health of veteran ... [12] Cross-cultural invariance of the basic psychological needs in exercise scale and need satisfaction latent mean differences among Greek, Spanish, ... [13] Act in practice: Case conceptualization in Acceptance ... [14] The interpersonal problems workbook: ACT to end painful ... [15] Acceptance and Commitment Therapy: An experiential approach to ... [16] Acceptance and commitment therapy, relational frame theory, and the third wave of ... [17] A practical guide toacceptance and commitment ... [18] Within-person variation in security of attachment: A self-determination theory perspective on ... [19] The relationship between basic need satisfaction and general healthof veteransofIsfahan's ... [20] The PTSD checklist (PCL), reliability, validity \& diagnostic utility. The 9th Annual ... [21] Evaluation of the effectiveness of acceptance and commitment-based ... [22] Validation of PTSD interview on veterans with war related physical ... [23] Addressing basic psychological needs fulfillment, autonomous ... 
نياز ذاتى روانشناختى وجود دارد كه عبارتاند از خودمختارى،

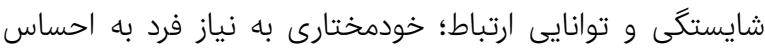

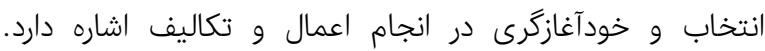
شايستخى، نياز به موثربودن در تعامل با محيط است و نشانداندهندا

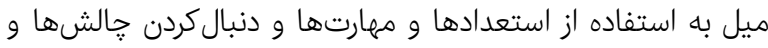

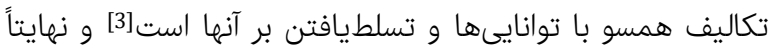

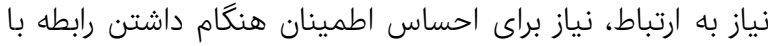

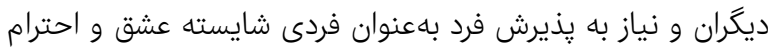

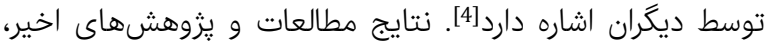

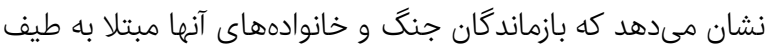

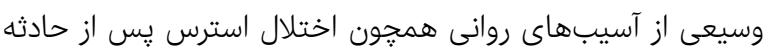
Post-Traumatic Stress Disorder; PTSD) خلقى و اضطرابى، يرخاشكرى، تعارض و افسردگى هستند [5].

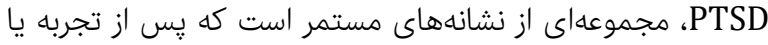

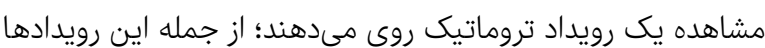

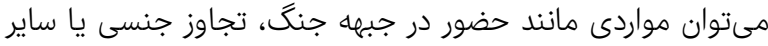

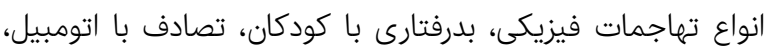

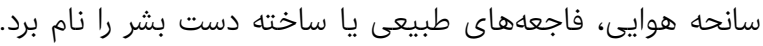

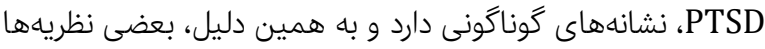

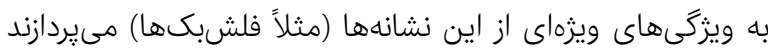
و بعضى ديكر به مسير زمانى اين اختلال و اينكه فرد آن را از از لحاظ

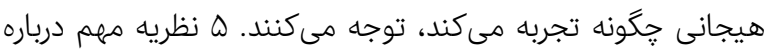

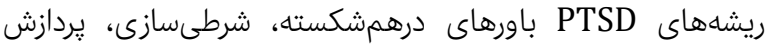

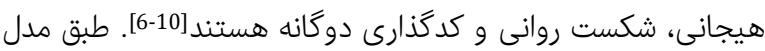

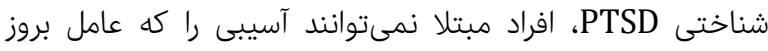

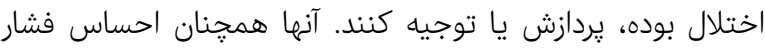

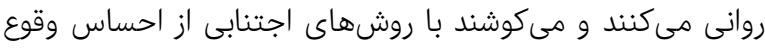

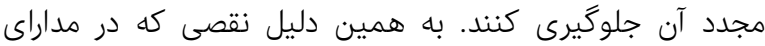

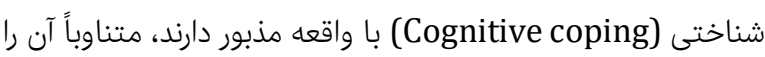

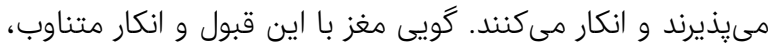

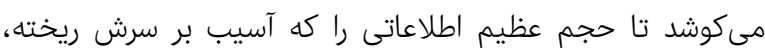
يردازش كند. مدل رفتارى PTSD حاكى از آن است كه إن بيدايش

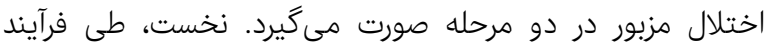

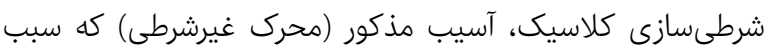
ايجاد يك واكنش هراسآور شده است، با محركى شرطى (يادآورى

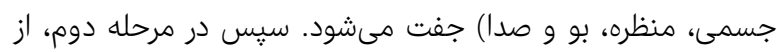

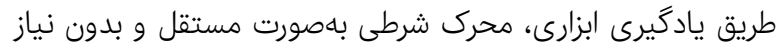

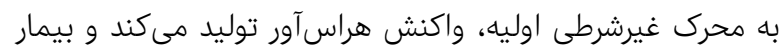

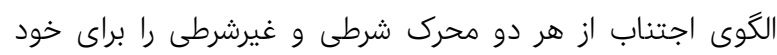

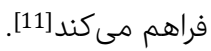
يكى از عواملى كه مىتواند بر نيازهاى روانى-اجتماعى جانبازان تاثير

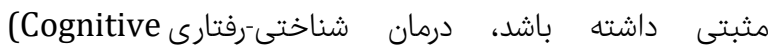
Behavioural Treatment; CBT)

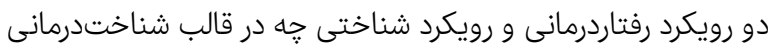

اثربخشى درمان شناختى-رفتارى و درمان مبتنى بر إنران يذيرش و تعهد بر نيازهاى روانى-اجتماعى جانبازان

PhD على Pغر اصغرنزاد فريد

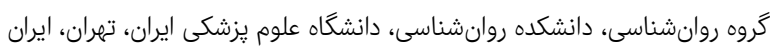

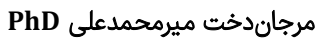

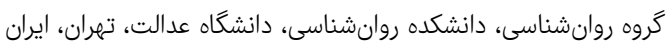
حسن احدى PhD

گروه روانشناسى، دانشكده روانشناسى، دانشگاه علامه طباطبايى، تهران، ايران على نصيرى برون بيمارستان روان يزشكى صدر، تهران، ايران

جكيده اهداف: اختلالات روانى مشكلى شايع در رزمندكان، جانبازان و خانوادههاى آنان

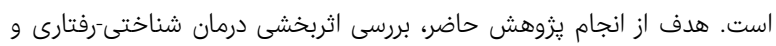

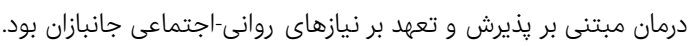

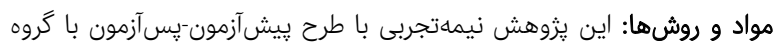

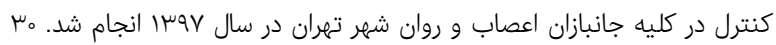

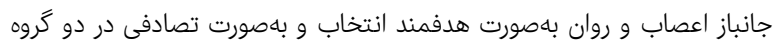

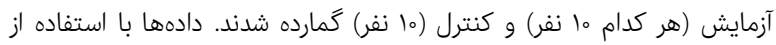

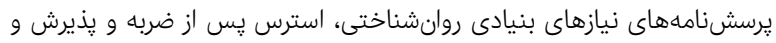

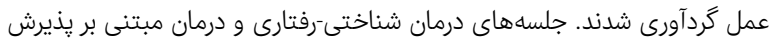

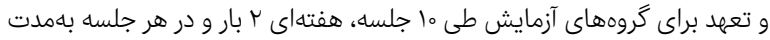

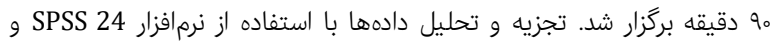

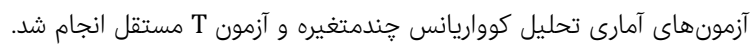

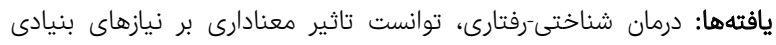

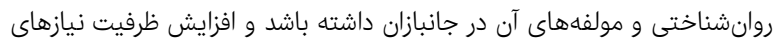

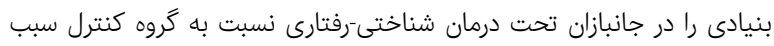

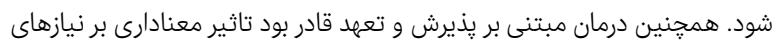

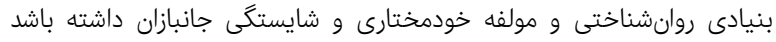

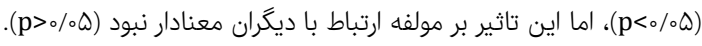

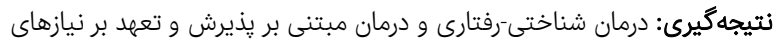
بنيادين روانشناختى جانبازان تانيان تاثير داردان

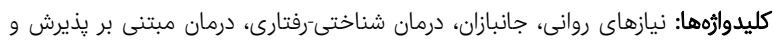

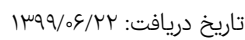

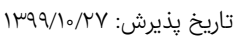

asgharnrjad.ali@gmail.com :نويسنده مسئول: تائوش:

مقدمه

جنگ، يكى از عوامل تاثيركذار بر ميزان شيوع، زمان شروع و سير

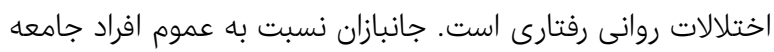

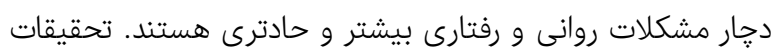

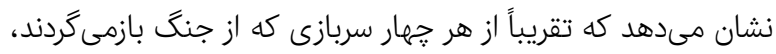

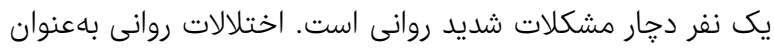

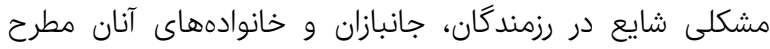

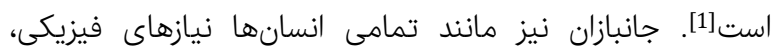

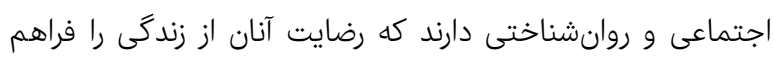

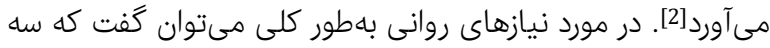


اثربخشى درمان شناختى-رفتارى و درمان مبتنى بر يذيرش و تعهد بر نيازهاى روانى-اجتماعى جانبازان 149

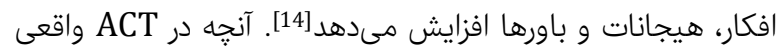

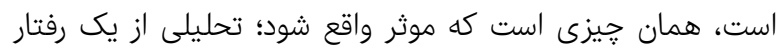

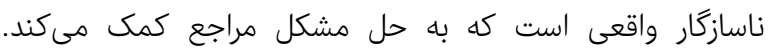

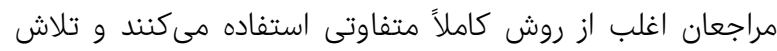

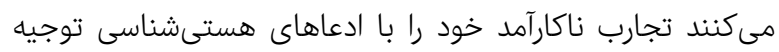

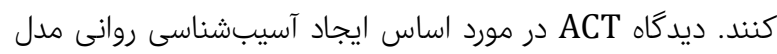
هنجار مخرب است؛ يعنى در ايجاد آسيبشناسى روانى فرآ درآيندهاى

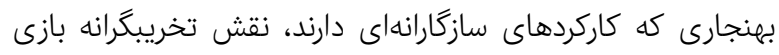

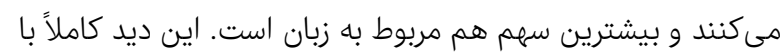

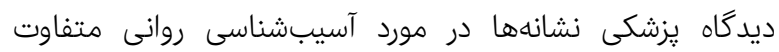

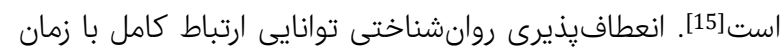

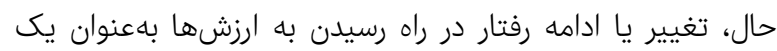

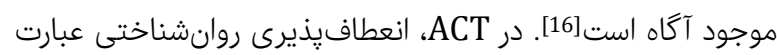

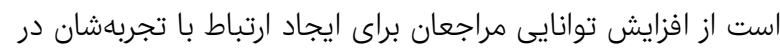

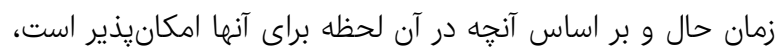

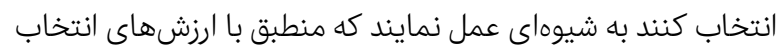

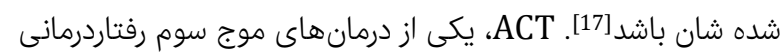

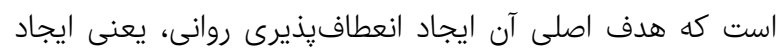

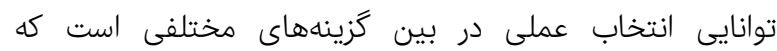

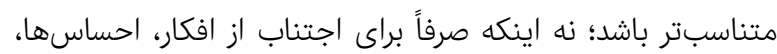

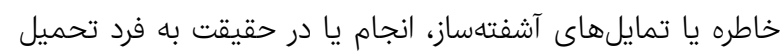

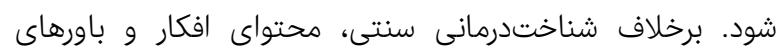

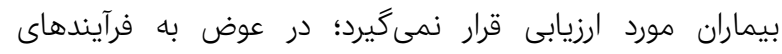
شكلگيرى آسيبشناسى روانى در بافت و زمينه مشكل توجه

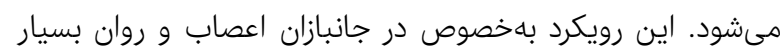

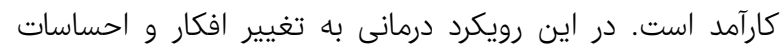

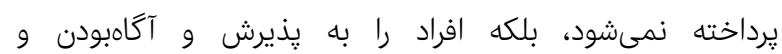

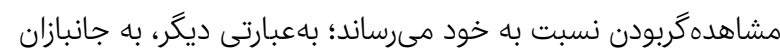

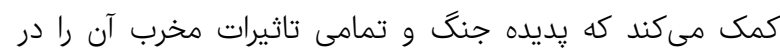

مرحله اول بيذيرند [4].

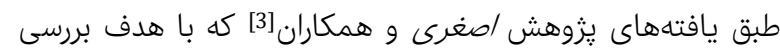

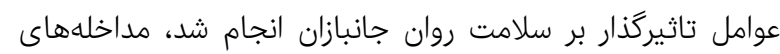

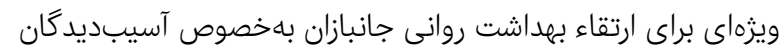
روانى مورد نياز است كه مىتوان دو نوع مداخله ACT و

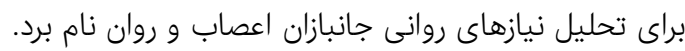

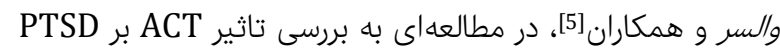

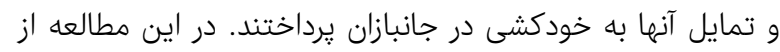

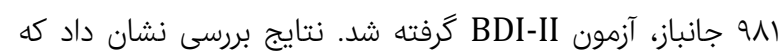

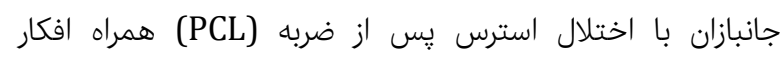

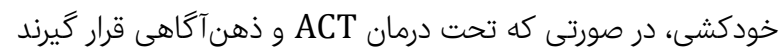

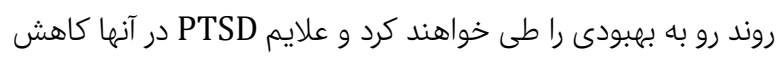
خواهد يافت. از سوى ديكر، CBT از درمانهاى موثر در تحليل نيازهاى روانى

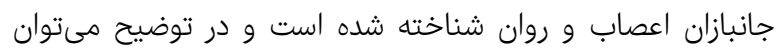

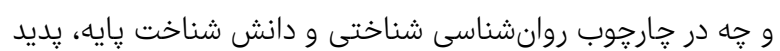

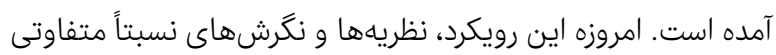
را در خود جاى داده است كه تنها وجه مشترك آنها، توجه به نقش إنش

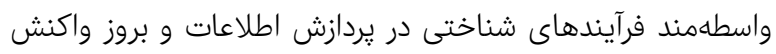

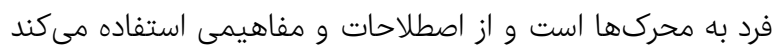

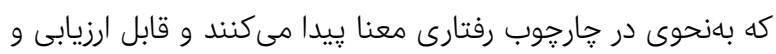

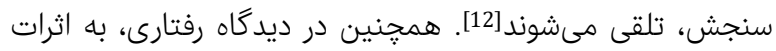
متقابل محيط و رفتار فرد، توجه مى كند. نظر رويكرد شناختى درباره

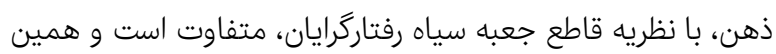

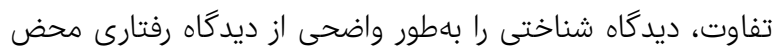

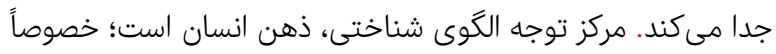

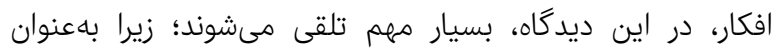

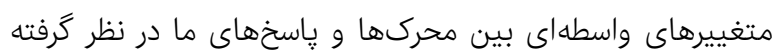

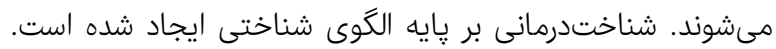
طبق الكوى شناختى، تفكر تعريفشده يا ناكارآمد، زمينهساز تمارئ لخدام

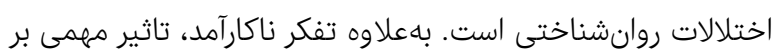

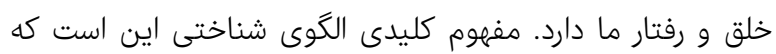

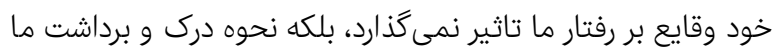

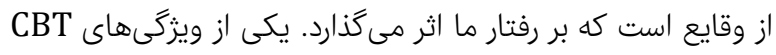

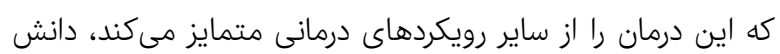
ساختار است. ساختار در CBT تعيين مىكند كه در هر مرحلهاى ازي راز

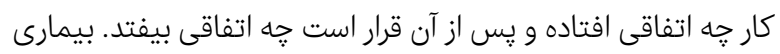

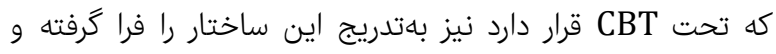

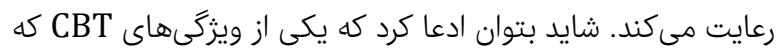

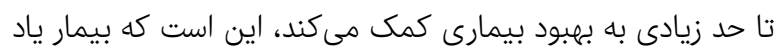

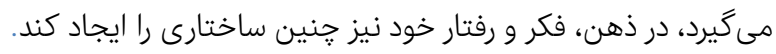

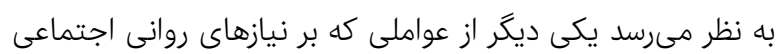

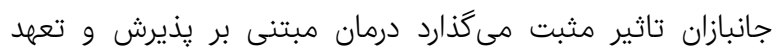
جاشانداز (Acceptance and Commitment Therapy; ACT) يك رويكرد درمانى بافتارى كارآمد، بر اساس نظريه جارجوب

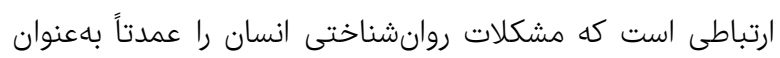

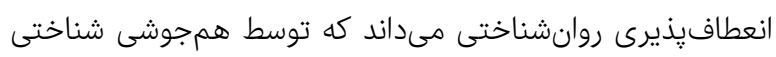

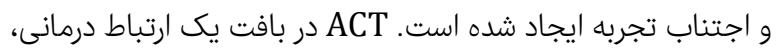
وابستخىهاى مستقيم و فرآيندهاى كلامى غيرمستقيم را بهابن إكار

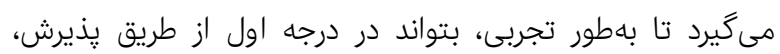
ناهمجوشى، ايجاد يك حس فراتجربى از خود، ارتباط با لحظه اكنون،

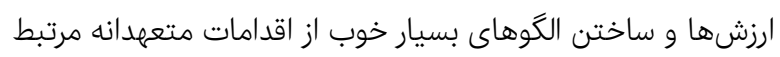

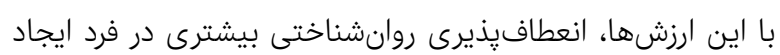

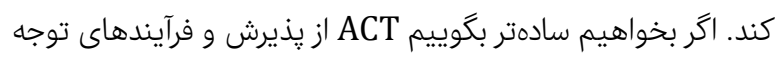

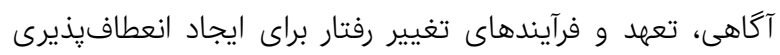

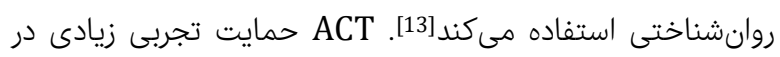

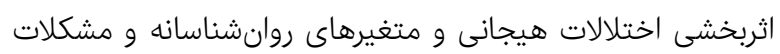

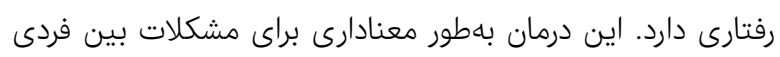

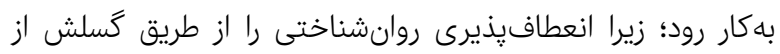


ورود موافقت براى شركت در طرح يزوهشى، زندگى كردن زن و شوهر

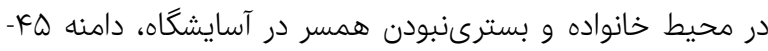

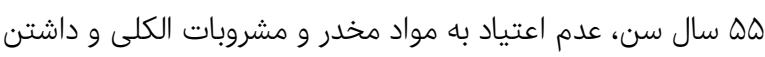

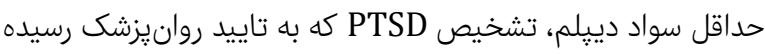

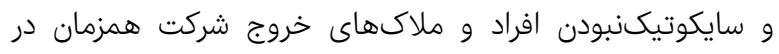
جلسات رواندرمانى و روانيزشكى، انتخاب شدند. تعداد نمونه با فران

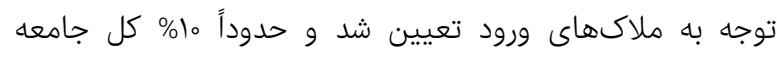
جانبازان اعصاب و روان شهر تهران بود. اين تعداد بر اساس نظر ولرد

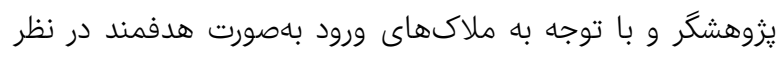
كرفته شد.

بر اساس ابزارهاى گردآورى اطلاعات زير، دادهها بهدست آمدند:

يرسشنامه نيازهاى بنيادى روانشناختى (Basic Needs) Satisfaction)

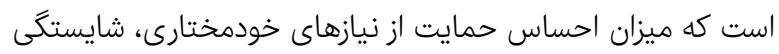

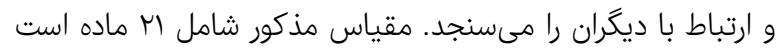

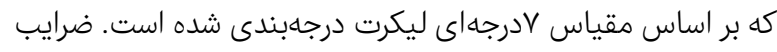

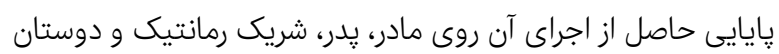

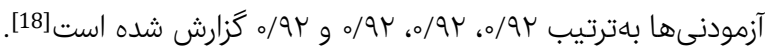
در ايران اين مقياس در نمونههاى مديران و دانشجويان ايرانى اجرا

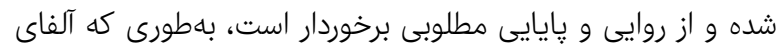

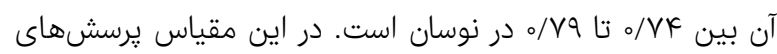

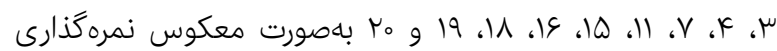

مىشود [19].

يرسشنامه استرس يس از ضربه (PCL): اين فهرست يك مقياس

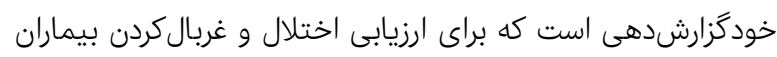

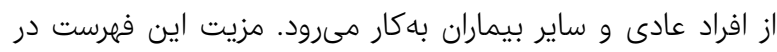

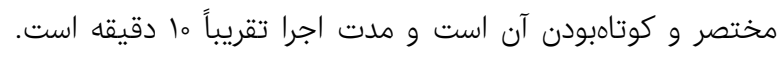

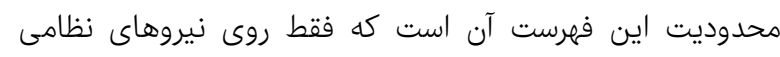

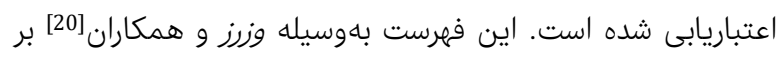

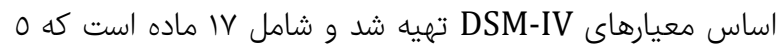
ماده آن مربوط به علايم تجربه مجدد حادثه، V ماده آن مربوط به ماده آنه

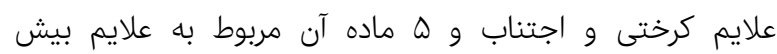

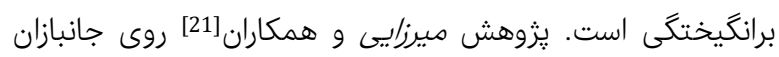

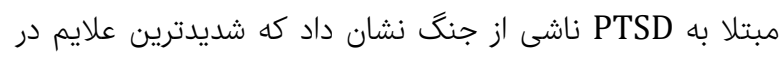

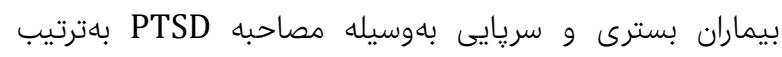

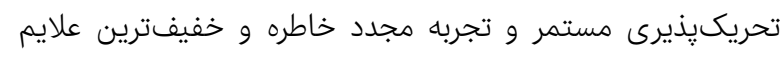

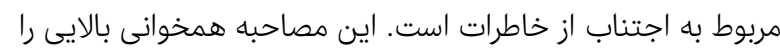

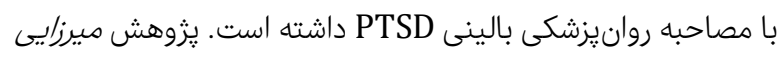

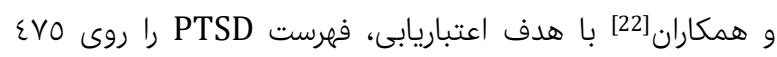

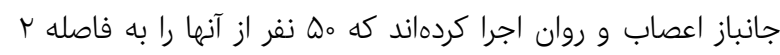

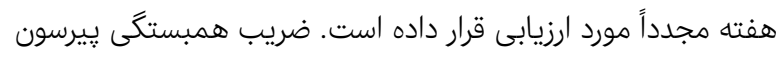

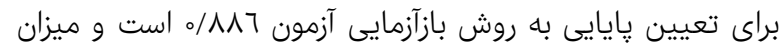

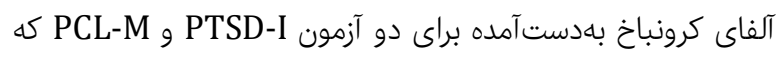

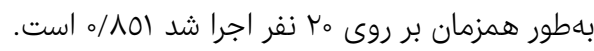

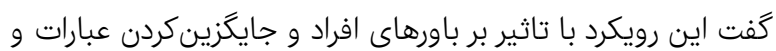
باورهاى مثبت بر ذهن و افكار آنان تاثير مى گذارند تا توانمندى أنها

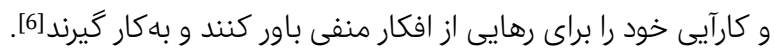
در CBT، روشهاى جديد انديشيدن و رفتاركردن به بيمار بهار آموخته مىشود تا آنها را جانشين نكرشهاى منفى جنى و معيوبى كند كه در مورد خود و جهان اطرافش در ذهن يرورش داده است، اين روش لهن

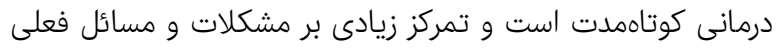

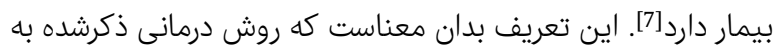

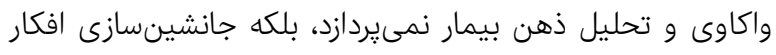
مثبت بهجاى افكار منفى و در واقع رهايى كوتاهمدتى رآى را از افكار

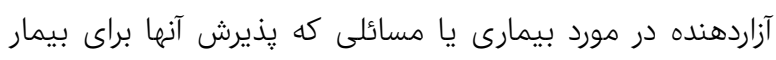

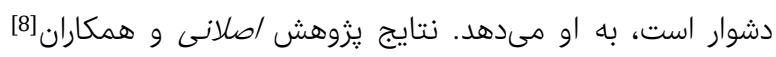

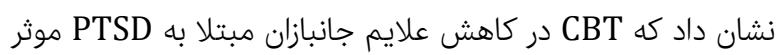

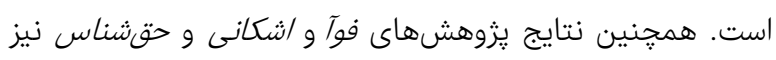
مويد اين موضوع است. شوبينا [9] در مرور تحقيقات انجامشده روى جانبازان مبتلا به PTSD موريت

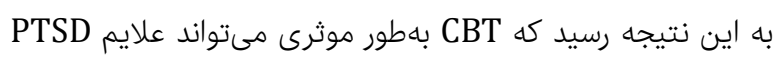

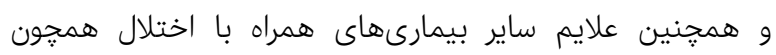
افسردگى و اضطراب را كاهش دهدين. هدف اصن اصلى اين شيوه درمانى،

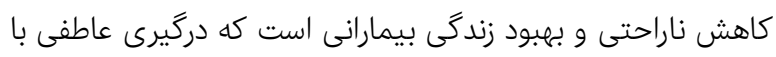

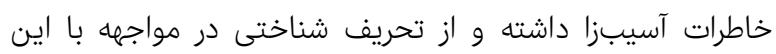

خاطرات رنج مىبرند. جانبازان يكى از اقشار جامعهاند كه بهلحاظ موند موقعيتشان بيشترين

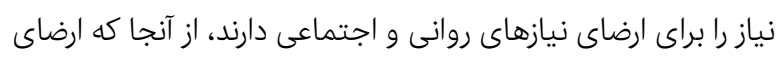

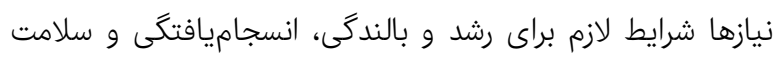

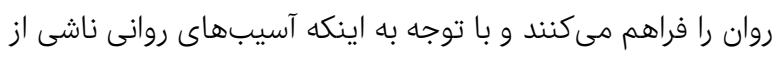
جنگ بلندمدت است و با كذشت مبر سال، هنوز اطلاعات موجود

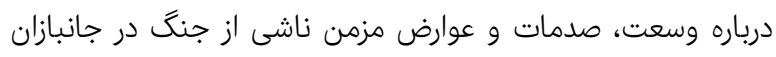

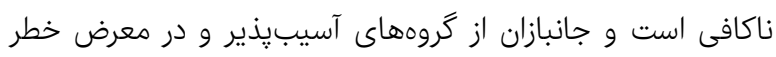

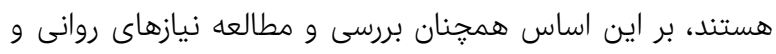

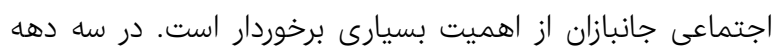
كذشته تحقيقات و مطالعات زيادى در حوزه سلامت روانى جارن جانبازان اندان

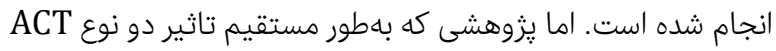

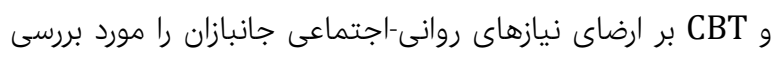

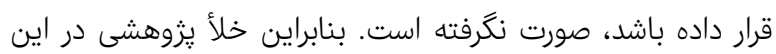

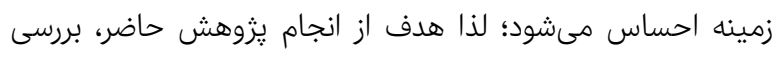

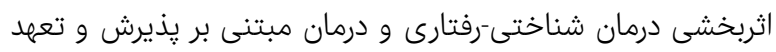

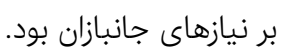

\section{مواد و روشها}

اين يزوهش از نظر هدف كاربردى و از نظر شيوه اجرا از نوع نيمه

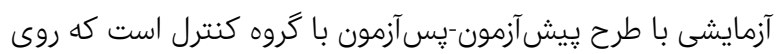

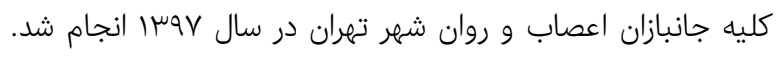
مب جانباز اعصاب و روان بهصورت هدفمند بر اساس ملاكنهاى 
جدول () خلاصه طرح درمان

\section{محتواى جلسات درمان} جلسه جله

درمان شناختى-رفتارى

آشنايى با بيمار، گرفتن شرح حال و اجراى برسشنامنه نيازهاى بنيادى روانشناختى.

آموزش مدل سامولفهاى اضطراب A-B-C و تاكيد بر انجام تكاليف خانكى.

آموزش در خصوص سير و ماهيت اختلال اعصاب و روان.

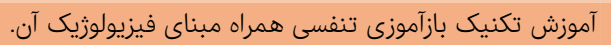

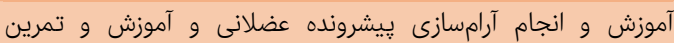
روشهاى كنترل اضطراب و استرس.

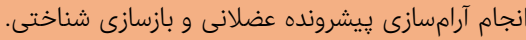

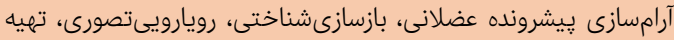
سلسله مراتب تمرينات رويارويى.

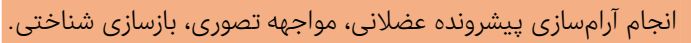

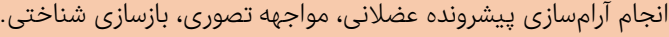

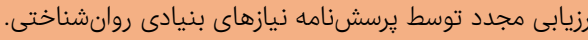

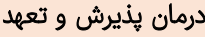

آشنايى با بيمار، كرفتن شرح حال و اجراى يرسشنامه نيازهاى بنيادى

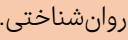

تشريح درماندگى خلاق با استفاده از استعارههاى ببر گرسنه و مسابقه

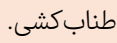

تشريح سم حصار ذهن و همجنين ڤِادزهر آن، يعنى رهايى از ذهن، تشريح و توضيح استعارههاى سهارًانه و عملكرد ذهن ذادن.

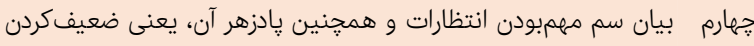
انتظارات با كمك استعاره جهار خواستًار.

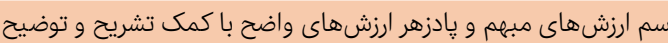

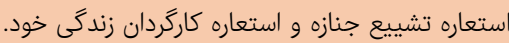

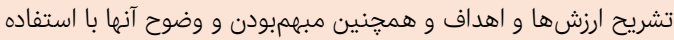

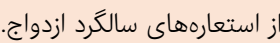

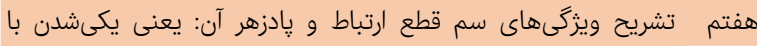
همسر. هشتم سم تمايل به اجتناب و يادزهر تمايل به بذيرش، تشريح اثرات اجتناب

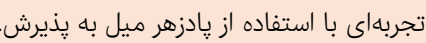

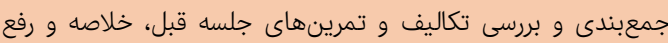
أشكال از مباحث بِيشين. دهم ارزيابى مجدد توسط يُرسشنامه نيازهاى بنيادى روانشناختى.

تجزيه و تحليل دادهها با استفاده از نرمافزار 24 SPSS و آزمونهاى

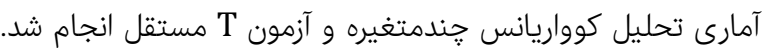

\section{يافتهها}

ميانگين نمره كل جانبازان در يرسشنامه نيازهاى بنيادى

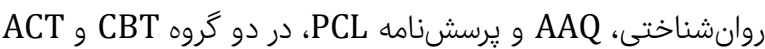

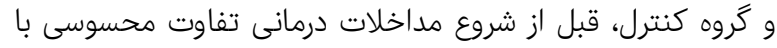

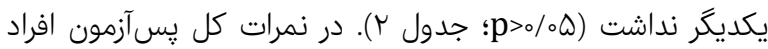

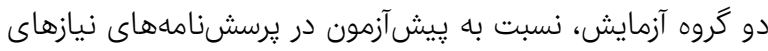

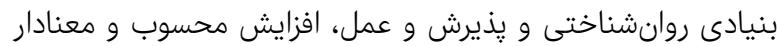

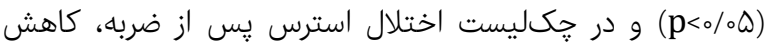

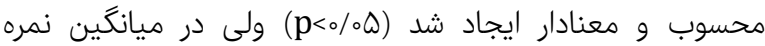

يرسشنامه پذيرش و عمل (AAQ): از اين يرسشنامه براى

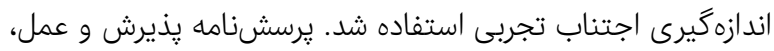

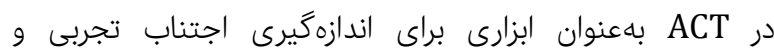

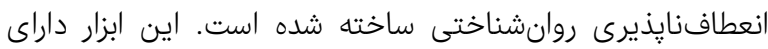

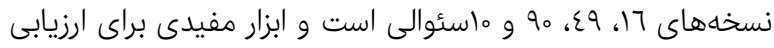

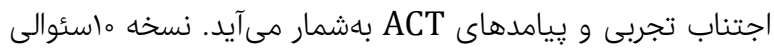

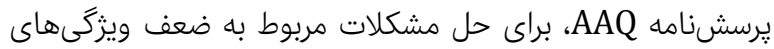
روانسنجى نسخههاى مختلف آن طراحى و اعتباريابى شده است.

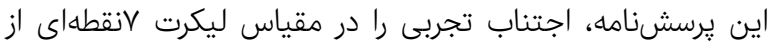

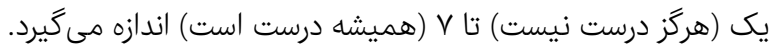

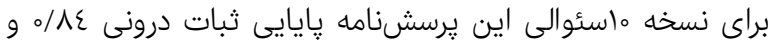

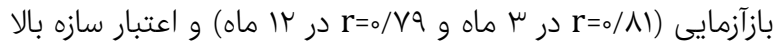

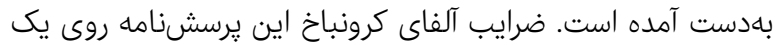

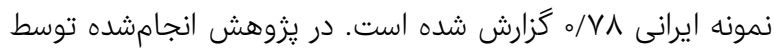

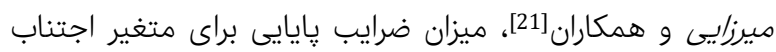

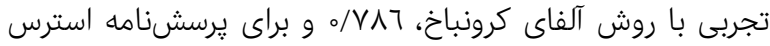

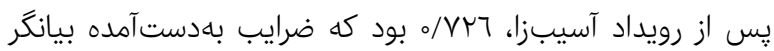

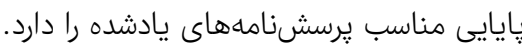

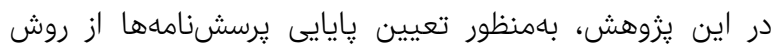

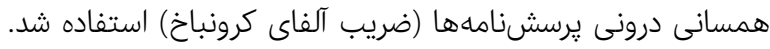

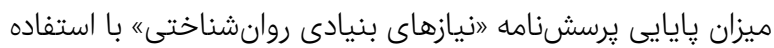

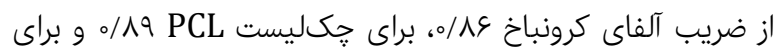

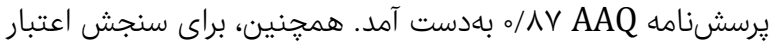

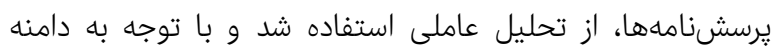

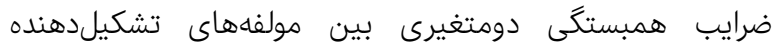

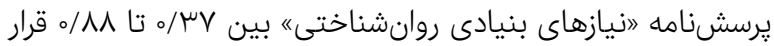

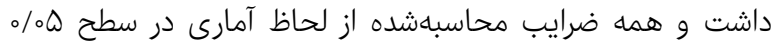
خطا تفاوت معنادار بود. دامنه ضرايب همبستگى دومتغيرى بين

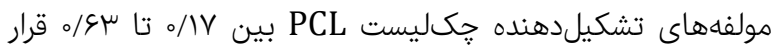
داشت و بهجز مولفه بيشبرانكيختگى كه با دو مولفه تجربه مجدد

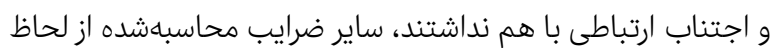
آمارى در سطح فه/ خطا، تفاوت معنادار داشتند.

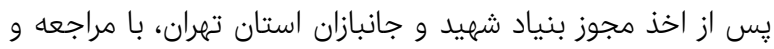

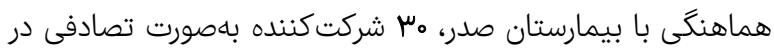

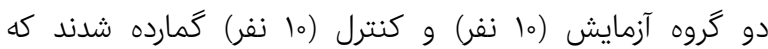

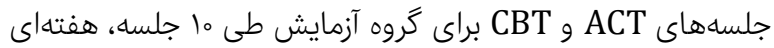

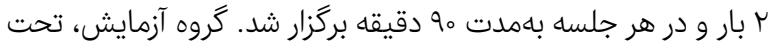

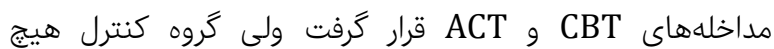
مداخلهاى دريافت نكرد. در شروع و يايان مداخله، يرسشنامنامهها بين

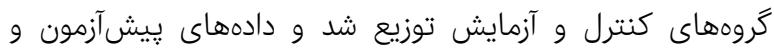

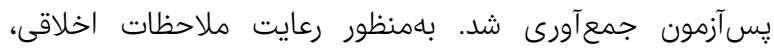

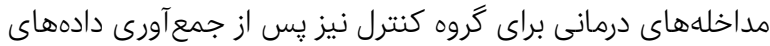

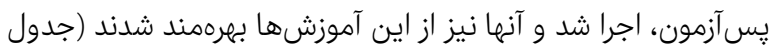


معنادارى وجود داشت؛ بنابراين مىتوان گفت كه ACT، توانست

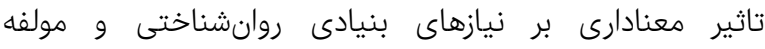

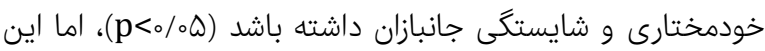

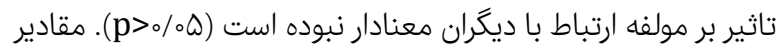

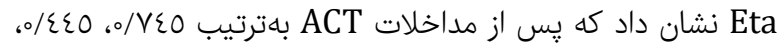

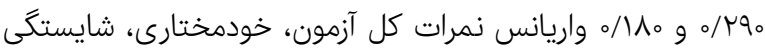

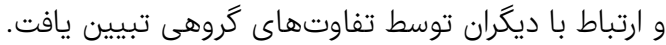

بحث

با بررسى نتايج بهدست آمده مىتوان كفت كه CBT، توانست تاثير

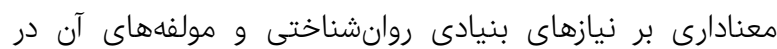
جانبازان داشته باشد و افزايش ظرفيت نيازهاى بنيادى برى را در جانبازان تحت CBT نسبت به گروه كنترل سبب شود. اين نتايج همسو بال نتايج بهدستآمده توسط كلهر[23] بود. وى در تاييد ديدگًاه ريان و و

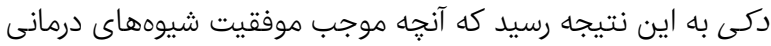

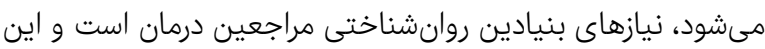
نيازها خود ييشبينى رينده مهمى براى سلامت روان و بهزيستى

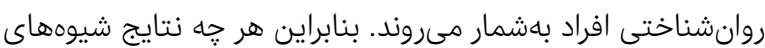

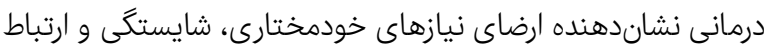

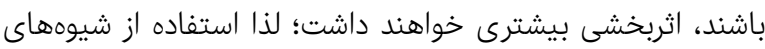

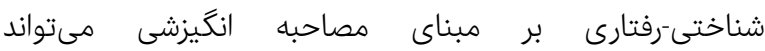

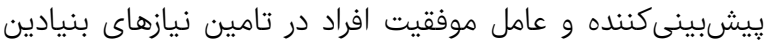

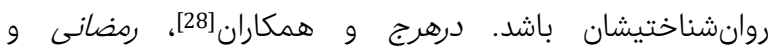

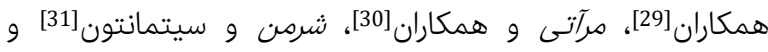

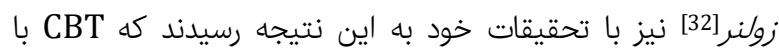

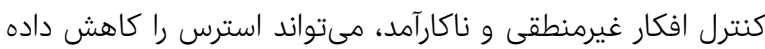

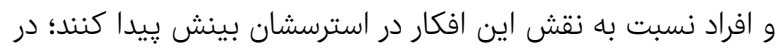

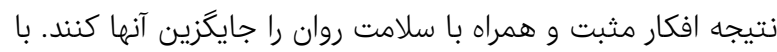

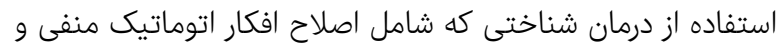

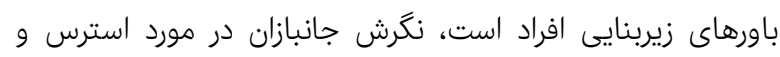

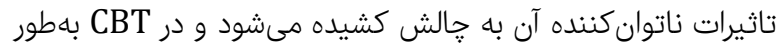
مشخص بر مولفههاى شناختى و فيزيولوزيكى استرس تاكيد

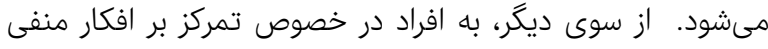

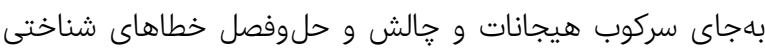
آموزش داده شد. به اين ترتيب، با افزايش استفاده از راهبردهاى

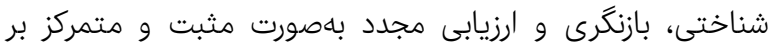
برنامهريزى قابل انتظار بود. تنظيم هيجانات مثبت مجاريت با كاركرد اجتماعى افراد مثل ارتباطات بين فردى رابطه دارد؛ افرادى كه از هازئ

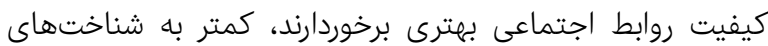

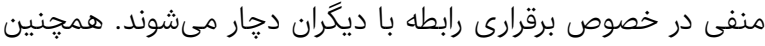

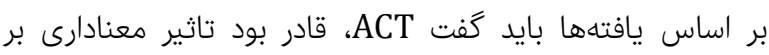

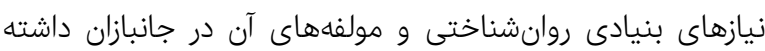

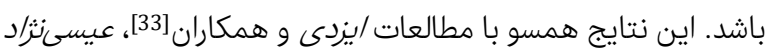

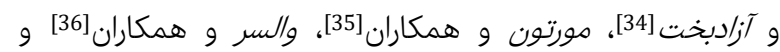

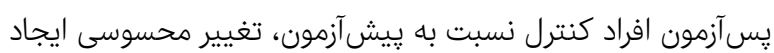

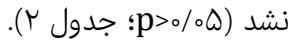

جدول r) نتايج ميانكَين نمره كل آزمودنىها در يرسشنامههاى مورد مطالعه

$\left(n=\mu_{0}\right)$

\begin{tabular}{|c|c|c|}
\hline "ِس آزمون & بيش آزمون & 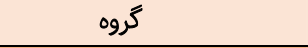 \\
\hline & & نيازهاى بنيادى روانشناختى \\
\hline$\varepsilon \mu / q_{0 \pm} \neq / q V$ & $\omega_{0} / \mathcal{K}_{\circ} \pm \varepsilon / K \mu$ & شناختى-رفتارى \\
\hline$\varepsilon r / / \Delta \pm V / \circ \mu$ & $\Delta 1 / \mathcal{F}_{0} \pm 9 / 91$ & درمان مبتنى بر يذيرش و عمل \\
\hline \multirow[t]{2}{*}{$\Delta \mid / \Delta_{\circ} \pm g / V K$} & $\Delta I / r_{0} \pm N / T K$ & 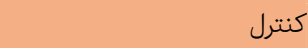 \\
\hline & & اختلال استرس يس از ضربه \\
\hline$\mu r / V \circ \pm r / ৭ \omega$ & $K_{0} / \varepsilon_{0} \pm r / r r$ & شناختى-رفتارى \\
\hline$\mu / \omega_{\circ} \pm \Psi / V \Lambda$ & $\xi_{0} / \Lambda_{\circ \pm} \pm / \circ \varepsilon$ & درمان مبتنى بر يذيرش و عمل \\
\hline \multirow[t]{2}{*}{$\mu V / \omega \circ \pm \psi / \varphi \Delta$} & $\mu N / K_{\circ \pm \pm \mu / N}$ & 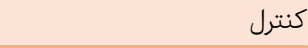 \\
\hline & & يذيرش و عمل \\
\hline$\Delta \mu / \mathcal{K}_{\circ \pm \mu / q \Lambda}$ & $K Q / g_{0} \pm F / \mu \mu$ & شناختى-رفتارى \\
\hline$\Delta \mu / \mu_{\circ} \pm \Delta / \mu \mu$ & $F \Delta / \mu_{\circ} \pm \varepsilon / \mu l$ & درمان مبتنى بر يذيرش و عمل \\
\hline$k Y / q_{0} \pm \varepsilon / q_{1}$ & $K V / \circ \pm E / R q$ & 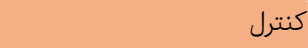 \\
\hline
\end{tabular}

نتايج آزمون كولموگروف-اسميرنوف روى متغيرهاى مورد مطالعه (بهجز متغير ارتباط با ديگران) نشان داد كه مىتوان دادهها را نرمال

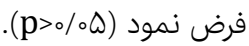

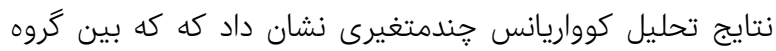

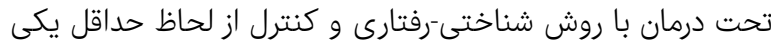

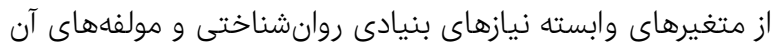
(خودمختارى، شايستگى و ارتباط با ديكران)، تفاوت معنادار وجود

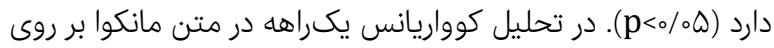

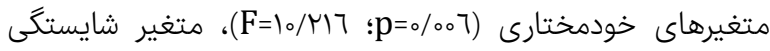

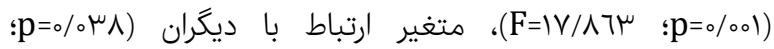

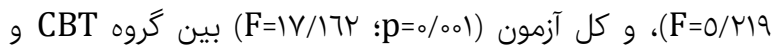

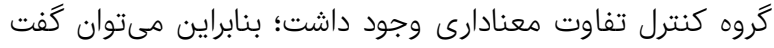

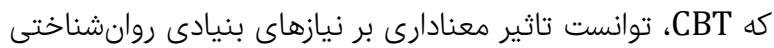

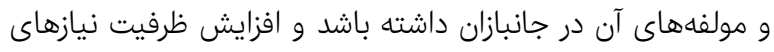

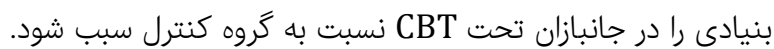

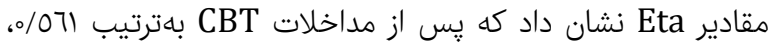

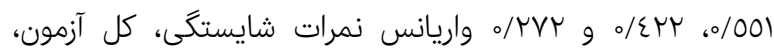

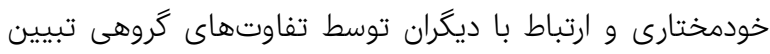

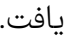
همجنين نتايج تحليل كوواريانس جندمتغيرى نشان داد كه بين

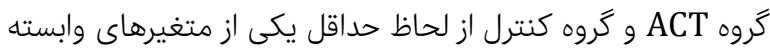

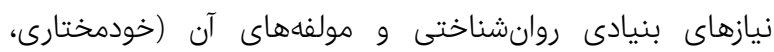

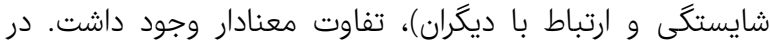

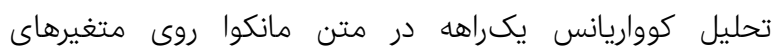
خودمختارى (F=0/\% (F=0/Vo。

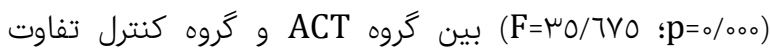




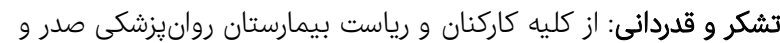

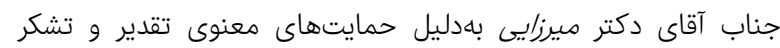

مىشود.

تاييديه اخلاقى: بدين وسيله نويسندًان تصريح مىنمايند كه هيجگَّنه

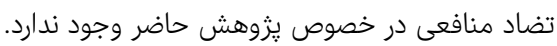

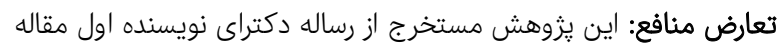

سهم نويسندگان: علىاصغر اصغرنزاد فريد (نويسنده اول)، نكارنده

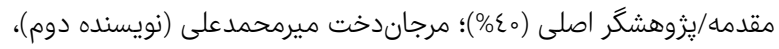

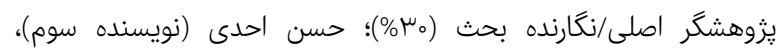

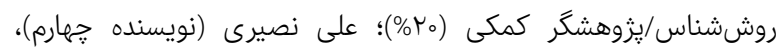
تحليلكر آمارى (10\%). منابع مالى: موردى براى گزارش وجود ندارد.

منابع

1- Ahmadi M, Noori T, Bahaadin Beigy K, Mehraeen E. Study of telemental health services for veterans from viewpoints of experts. PAYAVARD. 2016;10(1):12-22. [Persian]

2- Malkari B, Karimian N. Psychological-social consequences chemical bombardment of the Sardasht victims (a qualitative study). Iran J War Public Health. 2013;5(3):7-13. [Persian]

3- Asghari F, Sayadi A, Saadat S, Rashidi E. Prioritizing the needs of Guilan province's less than 25\%veterans from the viewpoint of them and their spouses. Iran J War Public Health. 2015;7(3):133-8. [Persian]

4- Mohagheghi H, Dousti P, Jafari D. The effectiveness of acceptance and commitment therapy on reduction, generalized anxiety disorder, social phobia and health anxiety in students. Clin Psychol Stud. 2016;6(23):81-94. [Persian]

5- Walser RD, Garvert DW, Karlin BE, Trockel M, Ryu DM, Taylor CB. Effectiveness of Acceptance and Commitment Therapy in treating depression and suicidal ideation in Veterans. Behav Res Ther. 2015;74:25-31.

6- Hoseinzadeh AA. The effectiveness of cognitivebehavioral therapy on increasing the mental well-being of addicts. Quart Psychol Educ Sci Stud. 2018;4(1):32-9. [Persian]

7- Sadock BJ, Sadock VA, Kaplan HI. Synopsis of psychiatry behavioral sciences/clinical psychiatry. Rezaei F, translator. 3rd Volume. Tehran: Arjmand; 2007. [Persian] 8- Aslani M, Hashemian K, Lotfi F, Mirzaei J. Effectiveness of cognitive behavioral therapy in war post traumatic stress disabled veterans. J Thought Bahav Clinic Psychol. 2007;1(3):6-17. [Persian]

9- Shubina I. Cognitive-behavioral Therapy of Patients with PTSD: Literature Review. Proced Soc Behav Sci. 2015;165:208-16.

10- Ganji M. Psychopathology based on 5-DSM. Tehran: Savalan; 2014. [Persian]

11- Salehi H, Ghamarani A, Salehi Z. The relationship between basic need satisfaction and general health of veteran sof Isfahan's Amiralmomenin Hosptital. Iran J War Public Health. 2014;6(2):1-9.

12- Vlachopoulos S, Asci FH, Cid L, Ersoz G, GonzalezCutre D, Moreno-Murcia JA, et al. Cross-cultural invariance of the basic psychological needs in exercise scale and need satisfaction latent mean differences among
ويرسب و همكاران[37] بود. آنها در بررسىهاى خود به اين نتيجه رسيدند كه راهبردهاى يذيرش و تعهد مىتوانند در نيازهاى بنيادى

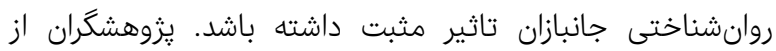

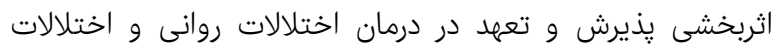

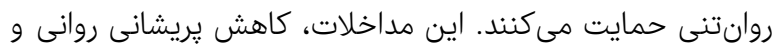

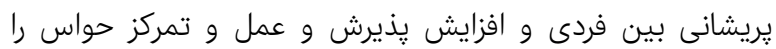

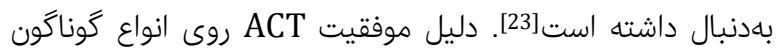

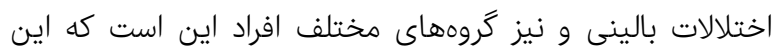

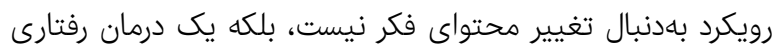

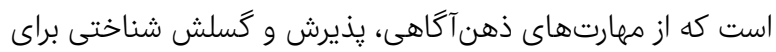

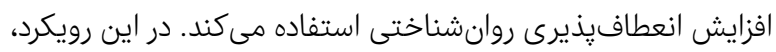

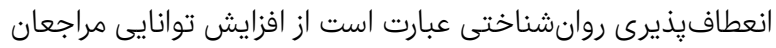

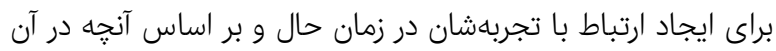

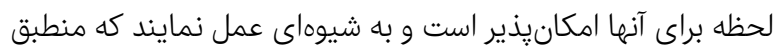

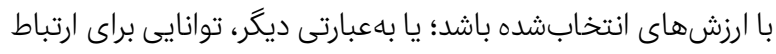

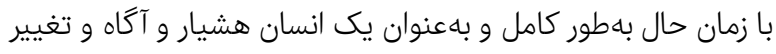

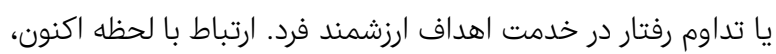

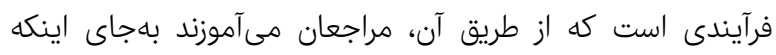

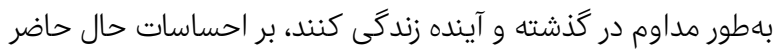

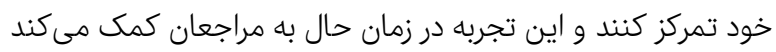

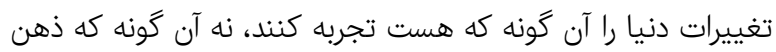
مى مسازد. تمرينات ذهن آكًاهى در ACT بهمنظور توجه مراجع به دنيا استفاده

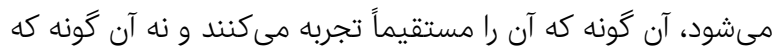

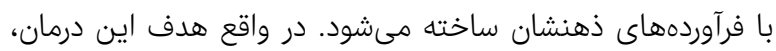

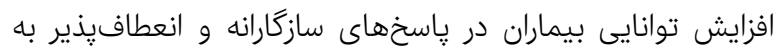

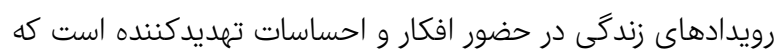

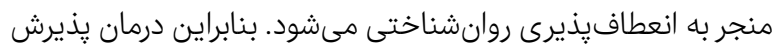

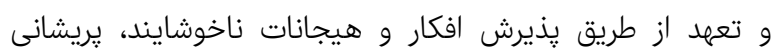

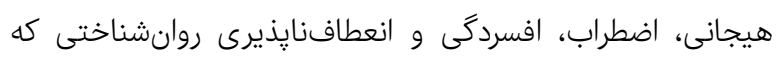

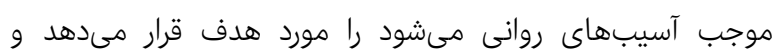

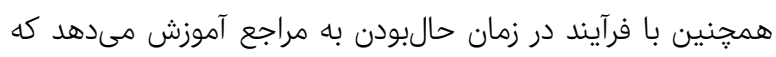

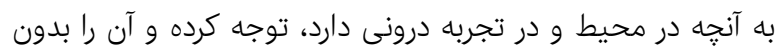

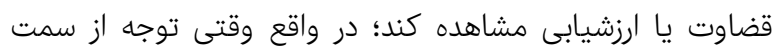
دنياى درون به محيط اطراف معطوف مىشود، إز از اين طريق آستانه

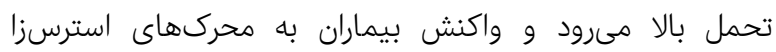
متعادلتر مىشود. يزوهش حاضر روى جانبازان شهر تهران انجام شد، لذا تعميم نتايج

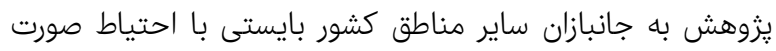

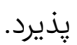
نتيجه درمان شناختى-رفتارى و درمان مبتنى بر هذيرش و تعهد بر نيازهاى بنيادين روانشناختى جانبازان مورد مطالعه تاثير دارد. 
19- Salehi H, Ghamarani A, Salehi Z. The relationship between basic need satisfaction and general healthof veteransofIsfahan's AmiralmomeninHosptital. Iran J War Public Health. 2014;6(2):1-9. [Persian]

20- Weathers FW, Litz BT, Herman DS, Huska JA, Keane T. The PTSD checklist (PCL), reliability, validity \& diagnostic utility. The 9th Annual Meeting of the international Society for Traumatic Stress Disorders Studies, 18 October, Sam Antoniou, TX, 1993.

21- Mirzaee Gh. Evaluation of the effectiveness of acceptance and commitment-based therapy on empirical avoidance, stress, anxiety, depression, and PTSD symptoms in Iran-Iraq war veterans [Dissertation]. Tehran: Ialamic Azad University, Scinece and Research Branch; 2018. [Persian]

22- Mirzaee J, Imani S. Validation of PTSD interview on veterans with war related physical and mental complications. Third Congress of Clinical Psychology Research, Imam Khomeini Hospital, 21-23 February 2011. [Persian]

23- Keleher B. Addressing basic psychological needs fulfillment, autonomous motivat, and working alliance in psychotherapy [Dissertation]. Waterloo: University of Waterloo; 2015.
| lek علىاصغر اصغرنزاد فريد و همكاران Greek, Spanish, Portuguese and Turkish samples. Psychol Sport Exercise. 2013;14(5):622-31.

13- Bach P, Moran DJ, Moran DJ. Act in practice: Case conceptualization in Acceptance and Commitment Therapy. Unknown City: New Harbinger Publications; 2008

14- McKay M, Fanning P, Lev A, Skeen M. The interpersonal problems workbook: ACT to end painful relationship patterns. Hamidpour $\mathrm{H}$, Mirzabeig AM, translators. Tehran: Arjmand; 2012. [Persian]

15- Hayes SC, Strosahl KD, Wilson KG. Acceptance and Commitment Therapy: An experiential approach to behavior change. New York: Guilford Publications; 2003. 16- Hayes SC. Acceptance and commitment therapy, relational frame theory, and the third wave of behavioral and cognitive therapies. Behav Ther. 2004;35(4):639-65. 17- Hayes SC, Strosahl KD. A practical guide toacceptance and commitment therapy. New York: Springer Science \& Business Media; 2010.

18- La Guardia JG, Ryan RM, Couchman CE, Deci EL. Within-person variation in security of attachment: A selfdetermination theory perspective on attachment, need fulfillment, and well-being. J Person Soc Psychol. 2000;79(3):367-84. 